\title{
ENTREPRENEURSHIP IN SMART CITY BOURGAS
}

DOI: http://dx.doi.org/10.18509/GBP.2020.39

UDC: 334.722$]: 711.45: 004.738 .5(497.231)$

\section{Antonina Atanasova}

\author{
Sofia University "St. Kliment Ohridski”, Bulgaria
}

\begin{abstract}
The concept of the smart city has become more popular in the recent years in Bulgaria. The city of Bourgas is the first smart city in the country, which has introduced smart technologies in urban environment.

The city of Bourgas is the fourth largest city in Bulgaria, but with the processes of urbanization, technological progress, many problems and challenges has arose, which has made municipal authority more concerned about the future. In the recent years the Municipality of Bourgas has made the first step toward smart city through smart technologies, sensors, cameras, installed in the different parts of the city area, which detect, monitor, analyze and predict all the processes in the territory.

Many projects in the city of Bourgas were realized in order to improve the quality of life, city environment, education and urban economy, such as smart city laboratory, e-hub, smart transportation, smart traffic lights and etc.

But technologies are not the only way, in which we can create a smart city. Therefore one of the main highlights of the smart city concept are the social and economic aspects in the processes of transformation.

In this way the city of Bourgas has introduced projects for smart entrepreneurship, through which people, especially young, educated, creative people, students and $\mathrm{PhD}$ students can elaborate their projects and the Municipality of Bourgas motivate them through grants, material support for project development, facilities, assistance from mentors who are mainly representatives of local businesses and etc.

Municipality of Bourgas has elaborated a program for business angels and startup projects, which motivate people to develop different project ideas and they receive financial and material support.

E-hub Bourgas project is a resource for all young people with ideas and willingness to work. All E-hub members gain access to a living environment where they can develop their project proposals and have access to mentors, who support them throughout the whole process. The purpose of this idea is to create a circular education environment and to close the entire cycle: education - ideas / projects - realization in the labor market in Bourgas.
\end{abstract}

This report is presented in 4 sections, including the foregoing introduction. Section "Smart entrepreneurial hub Bourgas" will reveal the project idea and the expected results of it. Section "Entrepreneurship in smart city" will show how city authority can manage urban innovations through smart entrepreneurship and what are the benefits from this.

Section 4 is for conclusion and aims to show how entrepreneurship is the most important step in the processes of transformation the city of Bourgas in smart city.

Key words: smart city, urban innovations, entrepreneurship, smart laboratory 


\section{INTRODUCTION}

Population growth in cities generate different economic, social, ecological, political problems and challenges for people and authorities. All of these problems require innovative and smart solutions and practices in order to meet these challenges.

The European Commission (EC) defines smart cities as places "where traditional networks and services are made more efficient with the use of digital and telecommunication technologies for the benefit of its inhabitants and business[1] According to the Manchester Digital Development agency, "a 'smart city' means 'smart citizens' - where citizens have all the information they need to make informed choices about their lifestyle, work and travel options. [2] The city itself is a multifunctional and complex object that can be represented as a demographic, ecological, transport, administrative-territorial and industrial production system.[3]

We can define smart cities as a complex system which includes different components: urban infrastructure, city-serving system, socio-demographic aspects, ecological aspects and etc.

Smart cities in economic and social terms are looking to the future. [3] The nature of the technology adoption is considered to help cities undergo socio-technical transitions and become smart cities. [4]

Smart cities are good places for development of business. They:

- Improve supply of homegrown talent;

- Enhance infrastructure enabling more to start and scale;

- Ensure better access to public procurement opportunities;

- Improve connectivity allowing businesses to provide more data-related services

\section{E-hub Bourgas}

The city of Bourgas in the resent years has become more smarter and has been realized some projects for smart urban planning. The main focus in the city of Bourgas are not only technological aspects of smart city, but socio-demographic and economic aspects are also important. In the resent years Municipality of Bourgas has elaborated some projects for entrepreneurship in smart city Bourgas.

First project which will be start its realization is E-hub Bourgas (Entrepreneurial hub Bourgas).

The main purpose of these idea is to turn the university into an entrepreneurial hub that offers resources, diverse networking opportunities, funding opportunities, office space for its students, $\mathrm{PhD}$ students and young faculty to generate ideas that will be transformed into start-up companies, business projects, and enterprises on the territory of the city. Thus, young people will become active agents of change, actually participate in the practice and in this way they can see realization of their ideas on the territory of Bourgas, which is a very strong motivation to live in the city.

E-hub Bourgas will provide training, support and mentoring for students and $\mathrm{PhD}$ students to help them to become entrepreneurs. Thus, partners, mentors, teachers, business organizations, Municipality of Bourgas will support young people in their efforts to find solutions for problems in their communities, workplaces and organizations. The main direction in which the work will be undertaken is for students to become agents of change.

The main goal of the project is to turn the university „Prof. Asen Zlatarov” into a place that provides opportunities for students and $\mathrm{PhD}$ students to realize themselves in the city where they live. In this way young educated people will want to stay in Bourgas to live 
and work, and on the other hand their ideas and projects will have a real opportunity to be realized in the city, which is a very important for the economic development of the city.

For this purpose, University "Prof. Asen Zlatarov", partners, Municipality of Bourgas and enterprises will prepare standards and requirements for application with projects in specific scientific / business fields. The financing will be through a special fund managed by university, business partners and Municipality of Bourgas.

The only important condition for participation in the projects is the applicants to be current students and PhD students in the university and other educational centers on the territory of the city.

The main objectives of the project are:

1. Training: Entrepreneurship courses which will be focused on educating entrepreneurs and leaders of the future

2. Collaboration - very close link between management, faculty and student groups, collaboration with business, research institutions, government organizations and local groups to offer ongoing support for students and young researchers.

3. Retain and attract young, highly educated people.

The basic idea behind the creation of this hub is that in most cases young people do not know how to elaborate and create an idea which will be transformed in a product. In order to be realized entrepreneurial ideas financial support as well as methodological, resource and mentoring are necessary.

Advantages of this project are free office space in a shared, shared environment, access to expert advice, support, funding, coaching, mentoring.

E-hub Burgas is a resource for all young people with ideas and willingness to work. All E-hub members gain access to a living environment where they can develop their project proposals and have access to mentors who can support them throughout the process. The purpose of this idea is to create a circular education environment and to close the entire cycle: training - ideas / projects - implementation.

The e-hub will have a close relationship with the Bourgas Incubator, where students and PhD students will develop their project proposals with business support. [5]

How an idea actually works?

1. Separate space in the university "Prof. Asen Zlatarov" or in the Incubator Bourgas, where with the financial support of the Municipality, university and enterprises, office spaces and separate offices will be formed, which are fully equipped with office furniture, with computers, printers, interactive boards, wi-fi, with IT management and personal assistant capabilities. These offices will be provided free of charge for one year to young entrepreneurs and start-ups, who, through preliminary competitive sessions twice through the year, are approved by a commission (representatives of the Municipality, university and business). Competitions will be call for proposals that have specific requirements and standards for project proposals, such as (value added for the city, green sustainable technologies, IT sector, etc.). Applicants must submit detailed projects that meet the requirements, with a business plan, budget, etc.

2. Brainstorming meetings will be organized once a month, where young people present their business ideas and are discussed by a wider range of experts.

3. Public lectures and training seminars from well-known names in business, IT sector, public administration, universities, sports, culture, ecology, etc. will be held regularly. 
4. Networking - E-hub will enable networking of its members, which is an additional option for resolving cases from a larger circle of people, as well as for developing clusters and joint projects between hub members.

Another project for smart entrepreneurship is a programme "Business angels". This is an initiative which support and contribute financially and in a participatory for the realization of interesting business ideas.

The idea is a simple, on the one hand people with project ideas (predominantly young) who do not have finances to realize them or the ability to borrow, and on the other hand are people with financial opportunities who are looking for fresh and innovative business projects in which they can invest, of course, with shareholding in the future project or a percentage from the profit.

In the role of business angels are involved Municipality of Bourgas and / or a consortium of local enterprises who see the opportunity to profit in this endeavor.

In this way young people in the city of Bourgas can develop their ideas, apply with it to the municipality or certain business organizations and get funding for it. Thus, a very effective symbiosis between students / PhD students and business could be obtained because:

1. First, the business can see ideas of young, active and creative people who could become part of their organization in the future.

2. Second, undergraduate students will have the opportunity to develop a project in a real business environment, to see how things happen in practice, for which they will gain experience and knowledge and will be financially rewarded, and could become part of the teams of companies, with whom they work and assist them to successfully complete their projects.

In the resent years the city of Bourgas has introduced innovative solutions in the field of smart urban planning - smart lighting, smart sensors, smart parking system, smart traffic lights and etc. Therefore last project idea of the city leaders is to be founded smart city lab. Its envisages that in this laboratory will be monitored the performance of all electronic devices in the city in real time - for traffic, air pollution, trash bin sensors, traffic lights and etc.

Thus, smart city laboratory will be giving a complete picture of the efficiency of these devices. It is an important tool for better urban planning and smart decision-making, given the rapidly changing urban environment and the growing needs of people. Furthermore, students will have the chance to participate in this lab and to propose and implement pilot innovative projects.

\section{CONCLUSION}

Smart city is an entrepreneurial city. The city of Bourgas in the last years has developed different innovative solutions and practices in the urban environment. City is intelligent when investments are not only in technologies, but in socio-economic aspects. In the resent years the city of Bourgas has become more smarter and has been realized some projects for smart urban planning. The main focus in the city of Bourgas are not only technological aspects of smart city, but socio-demographic and economic aspects are also important. Some important projects have been planned to be realized in the next years in the city of Bourgas - E-hub Bourgas, Business angels, with the main purpose - to stimulate and motivate young people in the Municipality of to develop innovative and smart economy. 


\section{REFERENCES:}

[1] https://ec.europa.eu/info/eu-regional-and-urban-development/topics/cities-and-urban development/city-initiatives/smart-cities_en, last accessed October 2019;

[2] MDDA website http://www.manchesterdda.com/smartcity/;

[3] Naydenov, Kl., Smart cities - the future of urban planning, 5th International Multidisciplinary Scientific Conference on Social Sciences \& Art SGEM 2018;

[4] Krishna, R., Kummitha, R., Smart cities and entrepreneurship: An agenda for future research, Technological forecasting and social change 149 (2019);

[5] https://www.burgas.bg/ 